\title{
El fallo "SIPOBA c. Ministerio de Trabajo": Seis errores teórico-conceptuales de la Corte Suprema de Justicia de la Nación y su impacto en la libertad sindical
}

\author{
The "SIPOBA c. Ministry of Labour" sentence: Six \\ theoretical-conceptual errors of the Supreme Court \\ of Justice of the Nation and its impact on freedom \\ of association
}

A sentença "SIPOBA c. Ministério do Trabalho": Seis erros teórico-conceituais do Supremo Tribunal de Justiça da Nação e seu impacto sobre a liberdade de associação

Le jugement "SIPOBA c. Ministère du Travail":

Six erreurs théoriques et conceptuelles de la Cour suprême de justice de la nation et leur impact sur la liberté syndicale.

Jorge Afarian ${ }^{1}$ | Universidad de Buenos Aires

Revista Derechos en Acción / ISSN 2525-1678 / e-ISSN 2525-1686

Año 4/№ 10 Verano 2018/2019 (21 diciembre a 21 marzo), 381-394

DOl: https://doi.org/10.24215/25251678e258

ORCID: https://orcid.org/0000-0002-9350-2768

Recibido: 05/01/2019

Aprobado: 20/02/2019

Resumen: En el presente trabajo señalaremos los errores teórico-conceptuales de la Corte Suprema de Justicia de la Nación en el fallo "SIPOBA c. Ministerio de Trabajo s/ley de asociaciones sindicales" en materia de

\footnotetext{
1 Abogado y Docente. Facultad de Derecho de la Universidad de Buenos Aires. Becario Doctoral UBACyT, financiado por la Universidad de Buenos Aires. Maestrando en Ciencias Sociales del Trabajo. Miembro del Proyecto de Investigación UBACyT: "La reforma constitucional argentina de 1949: alcances del constitucionalismo social argentino en perspectiva transnacional", a cargo de la Dra. Leticia J. Vita. C. e.: jorge.afarian@gmail.com.
} 
limitación de derechos colectivos laborales. Abordaremos críticamente sus fundamentos y conclusiones, contribuyendo a la discusión respecto de las maniobras argumentativas que posee la nueva composición del Máximo Tribunal en materia coercitiva de derechos fundamentales laborales, desviando el tratamiento de temas de gran importancia y estableciendo criterios que abonan sensibles restricciones de derechos. Adoptaremos un estilo que mezcla lo ensayístico con la doctrina jurídica, buscando una mayor agilidad en la lectura y entendimiento de temas de gran importancia.

Palabras claves: Corte Suprema de Justicia de la Nación - Fallo - Errores - Derechos colectivos laborales

Abstract: In this work, we will point out the theoretical-conceptual errors of the Supreme Court of Justice of the Nation in the ruling "SIPOBA c. Ministry of Labour s/ Trade Union Associations Act" in matters of limitation of collective labor rights. We will critically approach its foundations and conclusions, contributing to the discussion regarding the argumentative maneuvers that the new composition of the Supreme Court has on the coercive matter of labor fundamental rights, diverting the treatment of issues of great importance and establishing criteria that pay sensitive restrictions of rights. We will adopt a style that mixes the essay with the legal doctrine, seeking greater agility in reading and understanding of issues of great importance.

Keywords: Supreme Court of Justice of the Nation - Sentence - Errors Collective labor rights

Resumo: No presente trabalho, apontaremos os erros teórico-conceituais do Corte Suprema de Justiça da Nação na sentença "SIPOBA com Ministério do Trabalho sobre lei de associações sindicais", em matéria de limitação de direitos coletivos de trabalho. Abordaremos criticamente seus fundamentos e conclusões, contribuindo a discussão sobre as manobras argumentativas que tem a nova composição da Suprema Corte sobre a matéria coerciva dos direitos fundamentais do trabalho, desviando 0 tratamento de questões de grande importância e estabelecendo critérios que carregam restrições sensíveis de direitos. Adotaremos um estilo que mescle 0 ensaio com a doutrina jurídica, pesquisando a maior agilidade na leitura e entendimento de questões de grande importância. 
Palavras-chave: Corte Suprema de Justiça da Nação - Decisão judicialErros - Direitos coletivos de trabalho.

Résumé: Dans ce travail, nous soulignerons les erreurs théoriques et conceptuelles de la Cour Suprême de Justice de la Nation dans le jugement " SIPOBA c. Ministère du Travail s/ loi des associations syndicales " en ce qui concerne la limitation des droits collectifs du travail. Nous aborderons de manière critique ses fondements et ses conclusions, en contribuant à la discussion sur les manœuvres argumentatives que la nouvelle composition de la Cour suprême a sur la question coercitive des droits fondamentaux du travail, bases qui détournent le traitement de problèmes d'une grande importance, en établissant des critères restrictifs des droits. Nous adopterons un style qui mélange l'essai avec la doctrine juridique, en recherchant d'agilité en la lecture, et de compréhension de questions d'une grande importance.

Mot-clés: Cour suprême de justice de la nation - Jugement - Erreurs Droits collectifs du travail

\section{Tendencias regresivas actuales en materia de derechos laborales}

La Corte Suprema de Justicia de la Nación ha modificado su composición en reiteradas oportunidades los últimos años, y esta cuestión no es un tema menor, especialmente en el tema que nos ocupa. En efecto, la historia de esta sentencia comienza en 2012, cuando los jueces eran siete: Ricardo Lorenzetti, Juan Carlos Maqueda, Elena Highton de Nolasco, Carlos Fayt, Carmen Argibay, Enrique Petracchi y Eugenio Zaffaroni.

Luego de la muerte de Argibay y Petracchi en 2014 y la renuncia de Zaffaroni a finales del mismo año, sólo contábamos con Highton de Nolasco, Maqueda y Lorenzetti, por lo que fueron estos magistrados los encargados de presidir la Audiencia Pública celebrada el 13 de agosto de 2015.

Finalmente, en 2017 (año en que se dicta el fallo bajo comentario), con una composición de cinco jueces se dicta la 
sentencia definitiva, esta vez con dos nuevos magistrados designados por decreto del Presidente Mauricio Macri en diciembre de 2016, luego confirmados por el Senado Nacional en 2016: Carlos Rosenkrantz y Horacio Rosatti.

Esta sentencia trata la sindicación o agremiación de las FASP (siglas de "Fuerzas Armadas, de Seguridad y Policiales"), su vinculación con el convenio 87 de la OIT y el derecho interno argentino, analizando las razones por las que se les está vedada la constitución y el reconocimiento de sindicatos, contribuyendo a la discusión sobre la legitimidad de tales limitaciones.

El fallo "Sindicato Policial de la Provincia de Buenos Aires (SIPOBA) c. Ministerio de Trabajo s/ley de asociaciones sindicales", fue dictado el 11 de abril de 2017. Criticaremos brevemente los principales fundamentos, conclusiones y aparentes "olvidos" del voto mayoritario, en particular lo atinente al derecho internacional del trabajo y su relación con el derecho constitucional argentino.

La tendencia limitativa de derechos laborales colectivos de la nueva composición de la Corte Suprema no es una novedad. Muy por el contrario, el Tribunal Supremo ha establecido que sólo los sindicatos estatalmente reconocidos pueden ejercer el derecho fundamental de la huelga en el fallo "Orellano Francisco Daniel c. Correo Oficial de la República Argentina S.A s/juicio sumarísimo" (Corte Suprema de Justicia de la Nación, Sentencia O. 93. XIIX. RHE, 2016).

En escasas páginas, la Corte limita severamente la titularidad del derecho de huelga, sólo a los sindicatos simplemente inscriptos (aquellos que no poseen la personería gremial) y a los sindicatos con personería gremial. Ahora bien, ¿qué sucede con los grupos "informales" de trabajadores que no poseen reconocimiento administrativo por parte del Ministerio de Producción y Trabajo de la Nación? Simplemente no están habilitados para agremiarse.

De este modo, el Estado se atribuye una facultad de enorme trascendencia, porque es indispensable su reconocimiento 
institucional para que cualquier grupo de trabajadores (ahora sindicato simplemente inscripto) pueda ejercer un derecho que es incluso anterior e independiente de la existencia o no de una asociación sindical.

Pero no nos detengamos demasiado en esta sentencia. Sólo diremos que, en el mismo sentido a la que analizaremos en este breve comentario, la Corte utiliza las diversas fuentes del derecho (convenios de la OIT, tratados internacionales, doctrina y literatura especializada sobre la temática, leyes nacionales, entre otras), sólo en los pasajes y párrafos que justifican su doctrina restrictiva de derechos colectivos laborales. En el caso de "Orellano" es el derecho de huelga, y en el caso "SIPOBA", es el derecho de constituir sindicatos y su reconocimiento institucional por parte del Ministerio.

Creemos que la interpretación de la libertad sindical en la presente sentencia, en particular de los convenios 87 y 98 de la OIT, con el juego de nuestra Carta Magna (Const. 1994, art. 14bis), limita el alcance de las mencionadas normas internacionales hasta casi diluirlas, aseverando que hay "clases" de trabajadores y trabajadoras a los que en lo sustancial se les está vedada la capacidad de bregar por sus derechos laborales mediante asociaciones gremiales.

\section{Fundamentos del voto mayoritario}

A principios de abril de 2017, la Corte Suprema de Justicia ha denegado, por mayoría, la inscripción gremial, con la pérdida de todos derechos sindicales que ello implica, del Sindicato Policial de la Provincia de Buenos Aires ${ }^{2}$. Los votos mayoritarios fueron de los Ministros Ricardo Lorenzetti, Elena Highton de Nolasco y Carlos Rosenkrantz, mientras que la disidencia estuvo compuesta por los votos de Juan Carlos Maqueda y Horacio Rosatti.

En esta oportunidad, nos detendremos sólo en la decisión de la mayoría, puesto que consideramos es la que cuenta con

2 Es la primera vez que la CSJN se expide respecto de la sindicación de las fuerzas policiales. 
errores conceptuales, metodológicos, y hasta temáticos, que invalidan su razonamiento y la consiguiente resolución del caso. Lo dicho es aún más curioso debido a que, el 13 de agosto de 2015 se celebró una Audiencia Pública en el seno de la Corte Suprema, y de los fundamentos expuestos y las opiniones de los Ministros, podía inferirse una solución favorable a una ley de Parlamento que posibilite el ejercicio de los derechos gremiales por parte de las FASP.

La mayoría sustentó su decisión, en primer lugar, en la Convención Nacional Constituyente de 1957, y particularmente en la opinión de algunos convencionales que restringían el ejercicio de los derechos colectivos para la policía en el marco de la discusión del futuro artículo 14bis, en particular la del convencional Bravo. Basándose en aquellas fuentes, concluye que éste no se aplica a las fuerzas policiales.

Luego, y en lo que concierne al derecho internacional del trabajo, aseveró que tanto el convenio 87 sobre libertad sindical y protección del derecho de sindicación como el convenio 98 sobre derecho de sindicación y negociación colectiva, dejan al arbitrio de cada país la legislación sobre el derecho de sindicación de las FASP.

En lo que concierne a los tratados internacionales sobre derechos humanos, incorporados al texto de la Constitución Nacional por la reforma de 1994, del Pacto Internacional de Derechos Económicos, Sociales y Culturales (PIDESC, 8.2), del Pacto Internacional de Derechos Civiles y Políticos (PIDCP, 22.2) y la Convención Americana sobre Derechos Humanos (Pacto de San José de Costa Rica, CADH, 16.3), contienen clausulas limitativas, y aún prohibitivas, de la posibilidad de agremiación por parte de la policía.

A su vez, de acuerdo con el principio de gobierno federal que sustenta nuestro país, cada provincia tiene reservado para sí el derecho de dictar su propia legislación en materia de fuerzas de seguridad y policiales, lo que sucedió con la Ley 13.982 (2009) de la Provincia de Buenos Aires, que si bien en su articulado no prohíbe expresamente la sindicalización, sí lo 
hace con "actividades lucrativas o de cualquier otro tipo incompatibles con el desempeño de las funciones policiales" (art. 12, el énfasis es del autor).

En cambio, el decreto reglamentario 1050 (2009) de la citada ley estima que serán consideradas actividades incompatibles con el desempeño de la función policial: Participar en actividades políticas o gremiales, asistir a lugares o participar de reuniones que comprometan la dignidad o el decoro de la función policial (art. 42, inciso b.-).

Por otro lado, dentro del acápite que enumera las faltas graves que constituyen abuso funcional y en la que debe intervenir la Auditoría General de Asuntos Internos de la Policía, el decreto incluye: " $m$ )- Acatar decisiones de asociaciones gremiales o profesionales contrarias a la prestación normal de los servicios que le corresponden a la misión de la Policía, sea ostensible o encubiertamente".

Cabe agregar que la Corte realizó una interpretación amplia respecto del vocablo "ley". Las restricciones a los derechos deben ser impuestas no sólo por una ley aprobada por la legislatura provincial o por el Congreso, sino que también puede realizarse a través de otras normas delegadas (Corte Interamericana de Derechos Humanos, 1986).

\section{Seis errores técnico-conceptuales de la decisión mayoritaria}

A partir de una atenta lectura de los fundamentos y conclusiones expuestos por la mayoría de la Corte Suprema, podemos señalar seis conclusiones del Máximo Tribunal que consideramos contradictorias y que carecen de razonabilidad. Por supuesto, el número no se agota en seis, sino que optamos por señalar los más relevantes de acuerdo a nuestro criterio. Desarrollaremos a continuación cada uno de ellos.

1- En el considerando $9^{\circ}$ expresa que "la Constitución" ha excluido a ciertos grupos de trabajadores del derecho a constituir organizaciones gremiales, entre los que se encuentran las 
fuerzas policiales. Para sustentar esta aseveración, cita la opinión e intervenciones de diferentes convencionales constituyentes de 1957, en particular la del convencional Bravo.

Lo que la Corte Suprema ignora, es que las opiniones de los miembros de la Constituyente de 1957 se refieren al derecho de huelga, y no al derecho a conformar sindicatos. Resalta que "la buelga era para los convencionales el derecho sindical por antonomasia y el principal reclamo obrero" (considerando $9^{\circ}$ ), como si carecer del derecho de huelga (o limitarlo) pudiera significar el total desconocimiento de los demás derechos gremiales, contrariando además una norma fundamental como el futuro art. 14bis.

Independientemente de que el derecho de huelga es un derecho neurálgico para el ejercicio de derechos gremiales, no era el reclamo planteado por el sindicato, que era el reconocimiento estatal y su inscripción en el registro de asociaciones sindicales.

2- La Corte Suprema "olvida" el punto 2 del artículo $9^{\circ}$ del convenio 87 de la OIT (1948) y el punto 2 del artículo $5^{\circ}$ del convenio 98 de la OIT (1949), los que establecen que la ratificación de estos convenios no menoscabará las leyes, sentencias, costumbres o acuerdos que concedan a los miembros de las fuerzas armadas y de la policía los derechos garantizados en dichos convenios, todo ello de acuerdo con el párrafo $8^{\circ}$ del artículo 19 de la Constitución de la OIT. Esta salvedad, que forma parte de la misma normativa utilizada por la CSJN para negar el derecho de sindicación a la policía, ¿no podría referirse al art. 14bis que asegura un derecho de agremiación más amplio?

3- Expresa que si los convencionales hubieran querido otorgar en el artículo 14bis derechos sindicales a los miembros de la fuerza policial, lo habrían hecho expresamente. Por el contrario, no sólo no los incluyeron sino que les vedaron el derecho de huelga, el derecho sindical por excelencia.

Ello nos suscita otra pregunta: ¿Por qué deberían haber incluido "expresamente" a los miembros de la policía dentro de 
los derechos sindicales? Por otro lado, ¿qué es más relevante en términos de acceso a derechos fundamentales (y en cuestiones formales), lo dicho en la Convención Constituyente o lo efectivamente plasmado en la Constitución Nacional?

En efecto, los convencionales deliberadamente establecieron una cláusula abierta en materia de derechos laborales, no sólo gremiales, y eso se evidencia precisamente de la discusión de los vocablos "gremio" y "sindicato" en el seno de la Convención Nacional Constituyente, en la que primó el primero de ellos, más amplio y abarcativo de experiencias colectivas de trabajadores.

Por último, la Corte Suprema nuevamente confunde "derecho de huelga" con "derechos sindicales". Además, para justificar la exclusión del "derecho sindical por excelencia” por parte de "los convencionales", cita sólo la opinión del convencional Bravo, que si bien era la mayoritaria no era la más representativa.

4- En el considerando $13^{\circ}$ considera que "la manera" en que fue incluido el artículo 14bis por la reforma de 1957 y el proceder "uniforme e inequívoco" del Estado durante más de sesenta años obligan a concluir que los miembros de la policía no tienen derecho a constituir un sindicato. Finaliza el considerando expresando que el reclamo no puede ser atendido en base a lo que nuestra Constitución "dispone" en dicha norma. Como sabemos, el art. 14bis no establece restricciones al derecho a constituir gremios por parte de los trabajadores.

En esta oportunidad la Corte alude a la supuesta "intención" del gobierno de facto de aquella época, como si aquella cuestión bastara para denegar un derecho esencial, precisamente sesenta años después de la sanción de la Constitución, que debe ser interpretado en sentido amplio y dinámico.

5- La CSJN cita el mensaje de elevación de la ley 23.544 (1988), que ratificó el convenio 154 de la OIT sobre fomento de la negociación colectiva (1981). En dicho mensaje se propone la reserva que sus disposiciones no serán de aplicación para 
los integrantes de las fuerzas armadas y de seguridad. De esta manera, evidencia una "posición estatal" de no conceder derechos sindicales a la policía.

Sin embargo, la Corte Suprema (una vez más) ignora el resto del párrafo, que continúa de esta manera:

(...) en tanto que, en el ámbito de la administración pública, se hará efectivo [se refiere a la negociación colectiva] en oportunidad de entrar en vigencia la nueva legislación que regulará el desempeño de la función pública, en la cual se fijarán las modalidades particulares para la aplicación del aludido convenio (...)

6- Por último, alude a los pactos y declaraciones sobre derechos humanos incluidos en el bloque de constitucionalidad a partir de la reforma constitucional de 1994 los que, como aludimos anteriormente, habilitan la limitación o prohibición de la sindicación a través de las leyes internas. A continuación, cita toda la normativa interna provincial que prohíbe la agremiación, olvidándose (nuevamente) de la Constitución Nacional, la que establece derechos sindicales amplios.

Creemos que el posterior análisis sobre los alcances del concepto "ley", si bien no carece de importancia, no aporta conclusiones sustanciales a la cuestión, puesto que podrían ser tachados de inconstitucionales al contrariar disposiciones de nuestra Carta Magna además de los instrumentos internacionales de la OIT y de derechos humanos en general.

\section{Reflexiones finales: Más dudas que certezas}

A partir de este somero comentario, podemos concluir que esta sentencia constituye una regresión en materia de derechos laborales (en este caso, gremiales), pero es también un claro ejemplo de la modificación argumentativa, tanto en lo sustancial como en lo técnico, que está experimentando la Corte Suprema. Pasaron escasos años desde los numerosos fallos que exaltaban la persona del trabajador como "sujeto de preferente 
tutela constitucional" (Corte Suprema de Justicia de la Nación, Sentencia V. 967. XXXVIII. REX, 2004; Corte Suprema de Justicia de la Nación, Sentencia C. 2605. XXXVIII, 2004; Corte Suprema de Justicia de la Nación, Sentencia A. 1023. XLIII. RHE, 2010) pero la herida ya está más que abierta.

La doctrina de la Corte Suprema varía constantemente, y ello debido a razones no siempre jurídicas. Sería un desacierto que sus decisiones, y dada la impronta de dicho Tribunal como último intérprete constitucional de la Argentina, no se adapten a los tiempos en que dichas sentencias se dictan. Ello se explica aún más cuando la composición de la Corte se modifica sensiblemente entre decisiones que tratan sobre temas (y sujetos) similares.

Numerosos trabajos (Afarian, 2018; Capón Filas, 2017; Duarte, 2016 y 2018; García, 2016; Izaguirre, 2018; Zas, 2016) señalan las deficiencias de la actual composición de la Corte Suprema en materia de razonamiento judicial relativo a derechos laborales, señalando sus citas tendenciosas e inacabadas, además de diversas confusiones conceptuales en relación a la verdadera cuestión analizada en la sentencia.

Por otro lado, y si bien la tendencia negativa respecto de los derechos del trabajadores y trabajadoras no es exclusiva de la mayoría de los miembros de esta Corte (Corte Suprema de Justicia de la Nación, Sentencia G. 774. XLVII. RHE, 2014; Corte Suprema de Justicia de la Nación, Sentencia C. 1468. XLVII. RHE, 2015), podemos observar que tanto en "Orellano" como en el fallo bajo análisis hallamos un gran número de transcripciones incompletas o escogidas especialmente para justificar la postura restrictiva del Máximo Tribunal, y que redunda en una merma de derechos fundamentales.

Incluso, en algunos pasajes recurre a meras especulaciones sobre lo que pudieron haber pensado los convencionales constituyentes o la actitud del gobierno en aquella época, lo que deslegitima aún más la decisión por carecer fundamentos jurídicos. 
A mayor abundamiento, tanto en "Orellano" como en "SIPOBA", la Corte se remite ciertas opiniones (muchas veces minoritarias) de miembros de la Convención Nacional Constituyente de 1957 para justificar su decisión, haciendo caso omiso a lo que efectivamente fue plasmado en la norma.

En sentido contrario, los miembros de la minoría en "SIPOBA" (Ministros Maqueda y Rosatti) sustentan su postura más amplia en normas fundamentales como la Constitución, los tratados internacionales y los convenios de la OIT, sin aludir a las discusiones en el Poder Legislativo o en la Convención que dio a luz al artículo 14bis. Su argumentación es, según nuestra opinión, más llana y coherente con todo el bloque normativo constitucional.

Cabe agregar que los trabajadores y trabajadoras policiales ejercen una actividad que posee particularidades que hacen difícil la plena asunción de la totalidad de los derechos sindicales, pero con esto no queremos decir que se les nieguen lisa y llanamente (como lo hizo la Corte Suprema) todos ellos, y en especial el de agremiación, que es la base de todos los demás. ${ }^{3}$

De acuerdo con Capón Filas (2017): "El tema es un asunto muy importante, para no dejarlo pasar. ¿Y la Corte Suprema? Se equivocó. Así de simple". Nosotros no somos tan optimistas, y esperamos que estas "equivocaciones" no sean consuetudinarias (porque ya son sospechosas).

\section{Bibliografía}

Afarian, J. (2018). Constitucionalidad de la sindicación de las fuerzas armadas, de seguridad y policiales en Argentina: a propósito de la sentencia "SIPOBA c/. Ministerio de Trabajo. Derecho Y Ciencias Sociales, (19), 113-132. DOI: https://doi. org/10.24215/18522971e042

\footnotetext{
3 El Ministro Maqueda incluye en su voto el ejemplo de la Guardia Civil y la Policía Nacional
} en España, que es una ilustrativa experiencia respecto de la regulación de estos derechos. 
Capón Filas, R. (2017). Marco jurídico para la creación de sindicatos policiales en la Argentina. Microjuris. Recuperado de: https://aldiaargentina.microjuris.com/2017/07/15/marco-juridico-para-la-creacion-de-sindicatos-policiales-en-la-argentinacapon-filas-rodolfo/

Duarte, D. (2016). La titularidad del derecho de huelga no resuelve el conflicto. Revista de Derecho Laboral Actualidad (2), 289-304.

Duarte, D. (2018). El fallo "Rica" un caso de neto corte decadente. Revista en línea del Instituto de Estudios Legislativos. Recuperado de: http://www.ladefensa.com.ar/La\%20Defensa\%2020/ comentario-fallo-rica.-por-david-duarte.html

García, H. O. (2016). ¿Quiénes son titulares del derecho de huelga? (Sobre la doctrina sentada por la Corte Suprema en la causa "Orellano c. Correo Oficial de la República Argentina" y las inconsistencias de sus fundamentos). Revista Derecho del Trabajo (7), 1532-1545.

Izaguirre, F. (2018). Caso Rica c/ Hospital Alemán: el mensaje implícito que conlleva el fallo genera preocupación. Revista Norte. Recuperado de: http://revistanorte.com.ar/fallo-rica-chospital-aleman-el-mensaje-implicito-que-conlleva-debe-generar-una-justificada-preocupacion/

OEA, Corte Interamericana de Derechos Humanos (CIDH) (1986). Opinión Consultiva OC-6/86, La expresión "leyes" en el artículo 30 de la Convención Americana sobre Derechos Humanos. Recuperado de: www.corteidh.or.cr/docs/opiniones/ seriea_06_esp.doc.

Zas, O. (2016). Análisis crítico de la doctrina de la Corte Suprema de Justicia de la Nación Argentina en materia de titularidad del derecho de huelga. Revista Direito das Relações Sociais e Trabalbistas, 2(2), 84-125. Recuperado de: http://publicacoes.udf. edu.br/index.php/exemplo1/article/view/61

\section{Fuentes}

Congreso de la Nación Argentina (1957). Diario de Sesiones de la Convención Nacional Constituyente. Buenos Aires: Imprenta del Congreso de la Nación. 
Congreso de la Nación Argentina (15 de enero de 1988). Ratificación del Convenio 154 sobre el fomento de la Negociación Colectiva. [Ley 23.544 de 1988]

Congreso de la Nación Argentina (1994). Constitución de la Nación Argentina. Buenos Aires: Imprenta del Congreso de la Nación.

Legislatura de la Provincia de Buenos Aires (08 de abril de 2009). Régimen y Nuevo Escalafonamiento para el Personal de las Policías de Buenos Aires. [Ley 13.982 de 2009]

Gobierno de la Provincia de Buenos Aires (03 de julio de 2009). Reglamentación de la Ley $\mathrm{N}^{\circ}$ 13.982. [Decreto 1050 de 2009].

\section{Jurisprudencia}

Corte Suprema de Justicia de la Nación (07 de septiembre de 2004). Sentencia C. 2605. XXXVIII.

Corte Suprema de Justicia de la Nación (14 de septiembre de 2004). Sentencia V. 967. XXXVIII. REX.

Corte Suprema de Justicia de la Nación (07 de diciembre de 2010). Sentencia A. 1023. XLIII. RHE.

Corte Suprema de Justicia de la Nación (30 de diciembre de 2014). Sentencia G. 774. XLVII. RHE.

Corte Suprema de Justicia de la Nación (19 de febrero de 2015). Sentencia C. 1468. XLVII. RHE.

Corte Suprema de Justicia de la Nación (07 de junio de 2016). Sentencia O. 93. XLIX. RHE.

Corte Suprema de Justicia de la Nación (11 de abril de 2017). Sentencia S. 909. XLVI. RHE.

Corte Suprema de Justicia de la Nación (24 de abril de 2018). Sentencia R. 9. L. RHE. 